

\section{Talent Match Evaluation: A Final Assessment}

\section{Authors}

Chris Damm

Anne Green

Sarah Pearson

Elizabeth Sanderson

Peter Wells

lan Wilson

July 2020

DOI: 10.7190/cresr.2020.1739253459 


\section{Acknowledgements}

We are extremely grateful to all those who have helped in the course of the evaluation. We are particularly grateful to the staff, young people and board members of the 21 Talent Match partnerships who have given their time freely to support the evaluation. A mention should be made of partnership leads and those involved in setting up the Common Data Framework (CDF). We trust that in time the considerable benefits of the CDF will be seen in terms of contributing to a robust evidence base on which to design future policies and programmes.

A wide range of staff and committee members at The National Lottery Community Fund have helped, supported and advised upon the evaluation. Their time has been invaluable. We are particularly grateful to Jolanta Astle, Sarah Cheshire, James Godsal, Scott Hignett, Scott Hyland and Roger Winhall. We are also grateful to former National Lottery Community Fund colleagues Matt Poole, Linzi Cooke and Scott Greenhalgh who provided invaluable assistance at the start of the Talent Match Evaluation.

Lastly, we would like to thank the evaluation team at Sheffield Hallam University, the University of Birmingham, the University of Warwick and Cambridge Economic Associates: Duncan Adam, Gaby Atfield, Dr Sally-Anne Barnes, Nadia Bashir, Dr Richard Crisp, Dr Chris Damm, Dr Maria de Hoyos, Dr Will Eadson, Professor Del Roy Fletcher, Dr Tony Gore, Professor Anne Green, David Leather, Elizabeth Sanderson, Emma Smith, Louise South, Professor Pete Tyler, Sarah Ward and lan Wilson. We would also like to thank our former colleague Ryan Powell who supported the original evaluation design and engagement with all the partnerships.

Peter Wells (Evaluation Director) and Sarah Pearson (Evaluation Project Manager) 


\section{Contents}

Key find ings......

Lessons for future policy................................................................................................. ii

1. About the programme

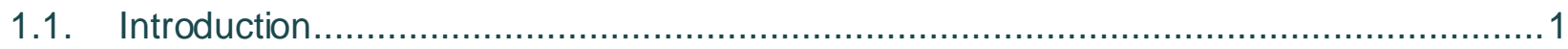

1.2. The case for supporting young people furthest from the labour market ........................2

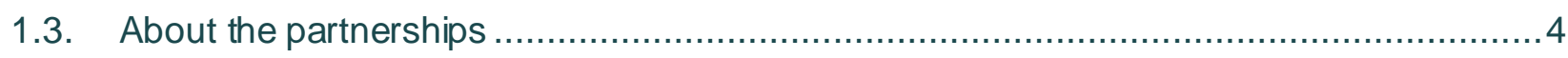

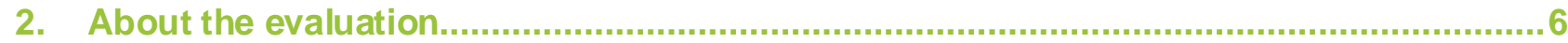

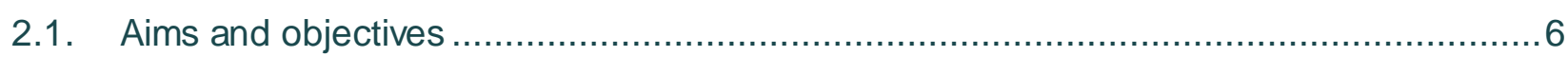

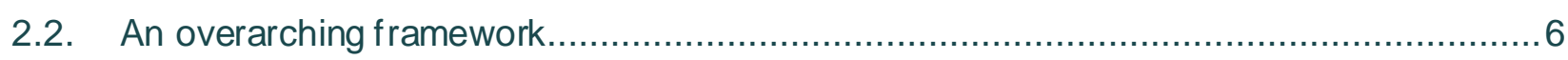

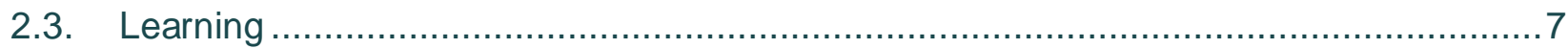

3. How was Talent Match delivered?

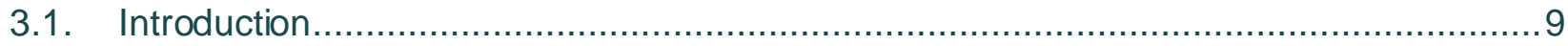

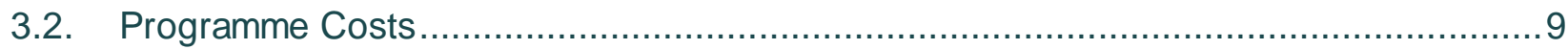

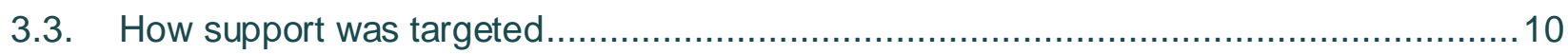

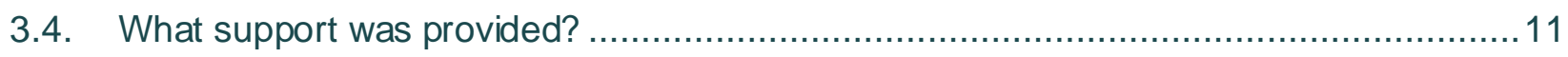

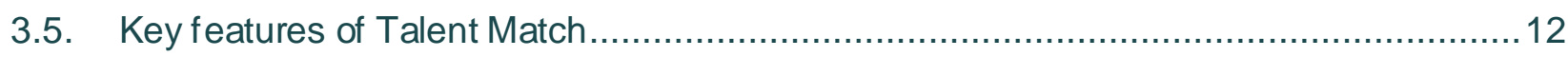

3.6. Who participated in Talent Match? .................................................................... 15

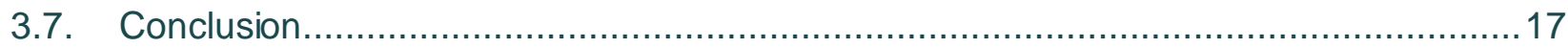

4. What has Talent Match achieved?

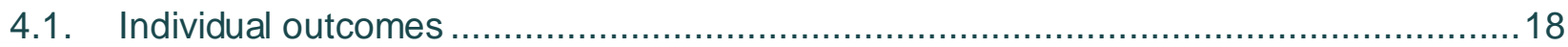

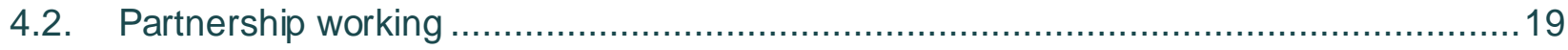

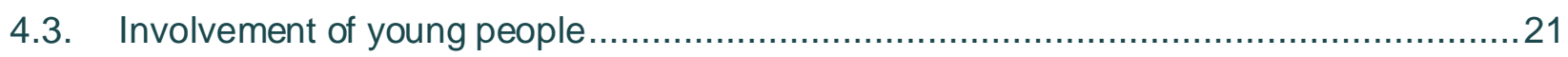

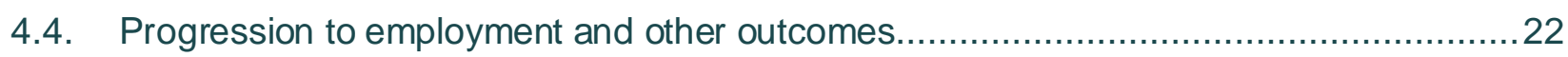

4.5. Talent Match legacy - the future of employment support for young people ...................24

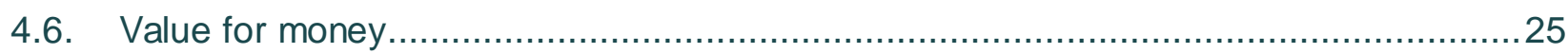

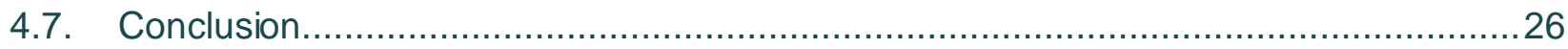

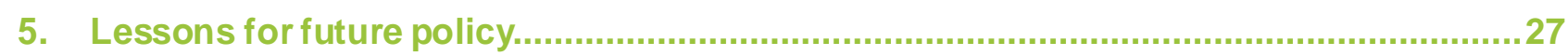

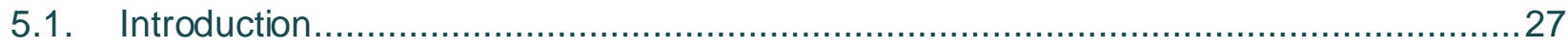

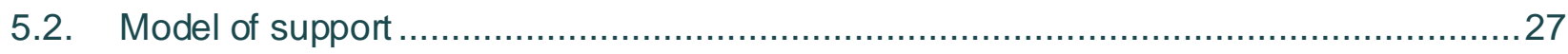


5.3. Labour market barriers and challenges faced by young people ...............................28

5.4. Understanding local labour markets and the needs of young people..........................28

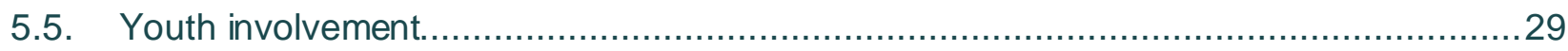

5.6. Person-centred approaches and key working.................................................. 30

5.7. Partnerships and the local employment support ecosystem....................................30

5.8. Improving effectiveness and increasing outcomes............................................ 31

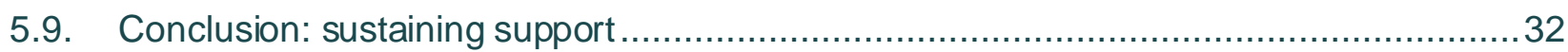




\section{Key findings}

Talent Match was a $£ 108$ million national lottery funded programme set up by The National Lottery Community Fund. It was launched in 2012 against the backdrop of record levels of youth unemployment and implemented from 2014-18. Funding was distributed to 21 voluntary and community sector led partnerships across England.

Four aspects of the programme were innovative and distinctive:

- Support was provided on a personalised and individual basis, responding to the needs of participants.

- The programme aimed to work with young people aged 18-24 who were furthest from the labour market.

- The programme was voluntary in contrast to government funded employmentprogrammes at the time.

- The programme was co-designed and co-delivered with the support of young people.

Some of the key findings from Talent Match include:

- A total of 25,885 young people were supported by Talent Match. Of these, 11,940 (46 per cent) secured some form of job, including 4,479 (17 per cent) who secured sustained employment or self-employment.

- Participants on the programme were broadly like the wider population of NEETs with three main differences: they were more likely to be male (63 per cent), on benef its (and therefore not hidden NEET), and more likely to have low life satisfaction.

- Talent Match participants moving into work reported high levels of job satisfaction.

- Talent Match helped support participants to improve their wellbeing: 70 per cent of those who gained a job reported improved life satisfaction; and 60 per cent for those who did not gain a job.

- At least $£ 3.08$ of public value has been generated for every $£ 1$ spent on Talent Match programme delivery. This means that there is a positive social benefit associated with Talent Match.

- Lead voluntary and community sector (VCS) partner organisations effectively engaged other organisations from across sectors. Nonetheless therewere challenges to partnership working, notably in terms of engaging Local Enterprise Partnerships and working with employers.

- The involvement of young people was the key feature of programme innovation and lessons on successful co-production can be drawn from Talent Match for future practice.

- Young people, especially those facing multiple barriers (including low skills, limited employment experience, homelessness and low levels of wellbeing) will continue to need support regardless of the state of the national economy and the level of unemployment. 


\section{Lessons for future policy}

The following implications for policy can be drawn from Talent Match:

- Labour market barriers and the challenges faced by young people: young people with of ten multiple needs continue to face significant barriers in entering employment, including low levels of wellbeing and poor mental health. Talent Match provides examples of how young people can be supported at a local level and confirms that this support for some needs to be provided over the long term.

- Understanding economies and the needs of young people: the use of employment data combined with local intelligence from young people and employers needs to be brought together more systematically to design and then refine labour market intervent ions.

- Youth involvement: the active involvement of young people in the design and delivery of the programme improved the quality of services provided, responded to the need expressed through the 'lived experience' of young people, and increased the program me's legitimacy.

- Person-centred approaches and key working: the value of high-quality relationships between participant and employment support provider was found to be crucial to initial and ongoing engagement. This was especially the case for young people furthest from the labour market. There were lessons from Talent Match as to how relational approaches to key working, mentoring and coaching could (and should) be embedded in future programmes.

- Partnership and local employment support ecosystem: Devolution may offer the opportunity to build local employment support ecosystems which can overcome some of the challenges of short-lived programmes interventions which have constrained employment support for a long time. 


\section{About the programme}

\subsection{Introduction}

Talent Match was an $£ 108$ million strategic programme funded by The National Lottery Community Fund (formerly the Big Lottery Fund and hereafter the Fund). Talent Match was launched in 2012 against the backdrop of record levels of youth unemployment and implemented between 2014-18. Funding was distributed to 21 voluntary and community sector led partnerships across England. The programme was one of five strategic programmes of The Fund, each with a common goal to support 'fulfilling liv es'.

Talent Match was an innovative and novel programme which focussed on bringing a youth centred, asset-based approach to the challenge of youth unemployment. Five defining features of the programme set it apart from any previous youth employment programme delivered at this scale in England:

- Support was provided on a personalised and individual basis, responding to the needs of participants.

- The programme aimed to support young people aged 18-24 years who were furthest from the labour market to make progress towards sustainable employment.

- The programme was voluntary (participation could not be mandated) which contrasted with government funded employment programmes at the time.

- The programme adopted a test and learn approach, designed explicitly to provide partnerships scope to develop and adapt bespoke solutions, which responded to local priorities and opportunities.

- And above all, the programme was co-designed and co-delivered with young people.

Unlike other mainstream employment interventions, Talent Match was not solely focused on the delivery of a narrow set of training and employment outcomes. Although helping young people to access job opportunities was an important goal for the programme, other goals were also integral to the approach. These included improving young people's well-being, developing responsive models of holistic support, building capacity in local areas to meet young people's needs, and increasing young people's influence on services.

The focus on developing more holistic and bespoke models of support also meant that Talent Match did not directly focus on achieving outcomes at a minimised cost. Whilst cost-efficiency is an important consideration for all public programmes, in Talent Match assessments of the costs and economic benefits of the programme need to be considered in the context of other programme priorities including youth engagement 
and local capacity building through partnership working. These are important caveats to the analysis presented in this report, and when comparing the costs and benefit of Talent Match against those of other programmes which might have narrower objectives.

\subsection{The case for supporting young people furthest from the labour market}

\section{Trends in youth unemployment}

Youth unemployment in the UK peaked at over one million in 2012. As Figure 1.1 shows this was a record high. Over the period from 1992 when data for young people are available the International Labour Organisation (ILO) unemployment rate for 1824-year olds remained considerably higher than for those aged 16-64 years. The increase in the ILO unemployment rate in the 'Great Recession' was much more marked for young people than for all adults. The ILO unemployment rate for 18-24 year olds rose from slightly over 10 per cent between 2000 and 2004 to 12.2 per cent in 2006 and 2007 and 17.3 per cent in 2009 , peaking at 19.3 per cent in 2012 before declining to 13.2 per cent in 2015 and 10.2 per cent in 2018.

Figure 1.1: ILO unemployment rate in the UK, 1971-2018

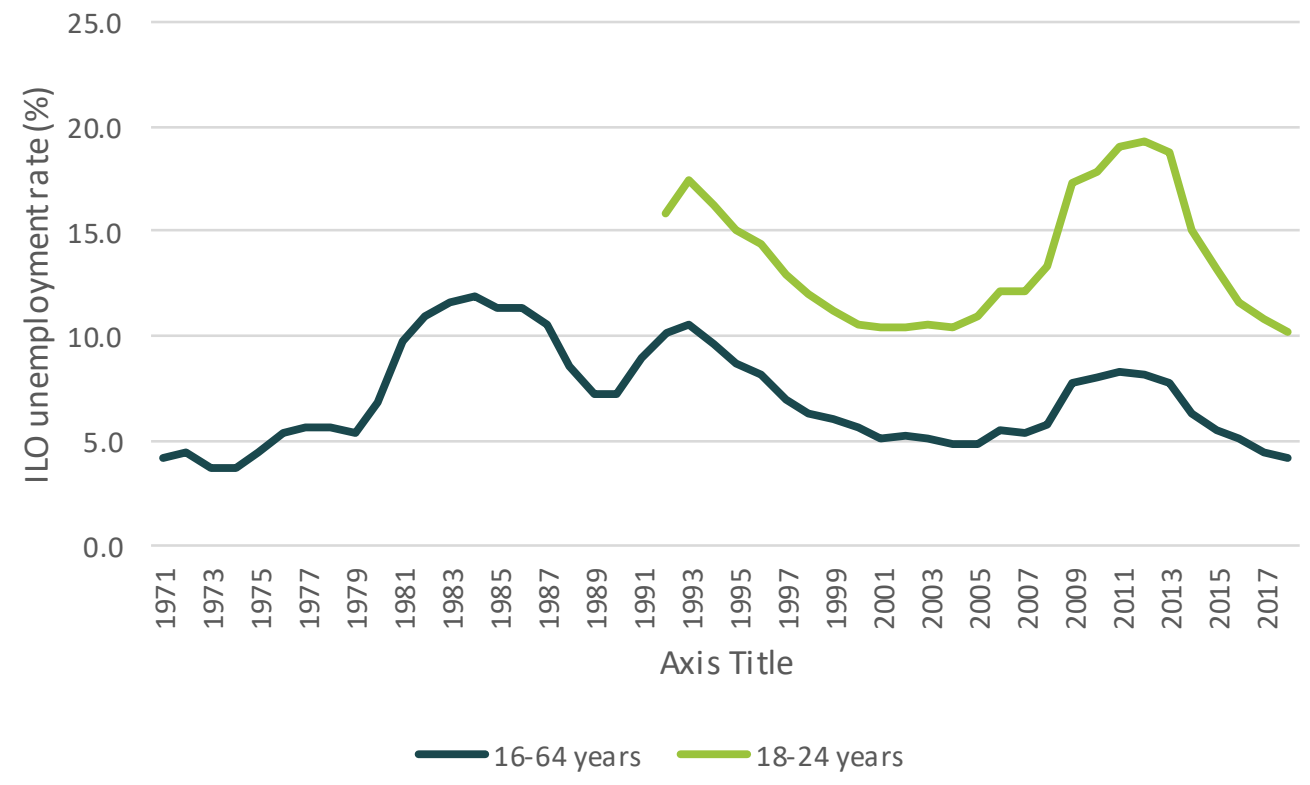

Source: Labour Force Survey (via Nomis)

The rise in youth unemployment at the time Talent Match was conceived and designed also spawned the introduction of other initiatives (nationally and locally) seeking to help young people into employment. By the time that Talent Match (and other local initiatives) was implemented, youth unemployment was still relatively high, but it was declining.

Figure 1.2 shows trends in the Jobseeker's Allowance (JSA) claimant count for 18-24year olds in the UK over the period from 1996 to 2017, distinguishing between those claiming for more than and less than six months. The number of JSA claimants in this age group peaked in 2009 and 2011 at around 460,000. Hence the claimant count declined markedly during the period when Talent Match was implemented. 
Figure 1.2: JSA claims in the UK, 1996-2017

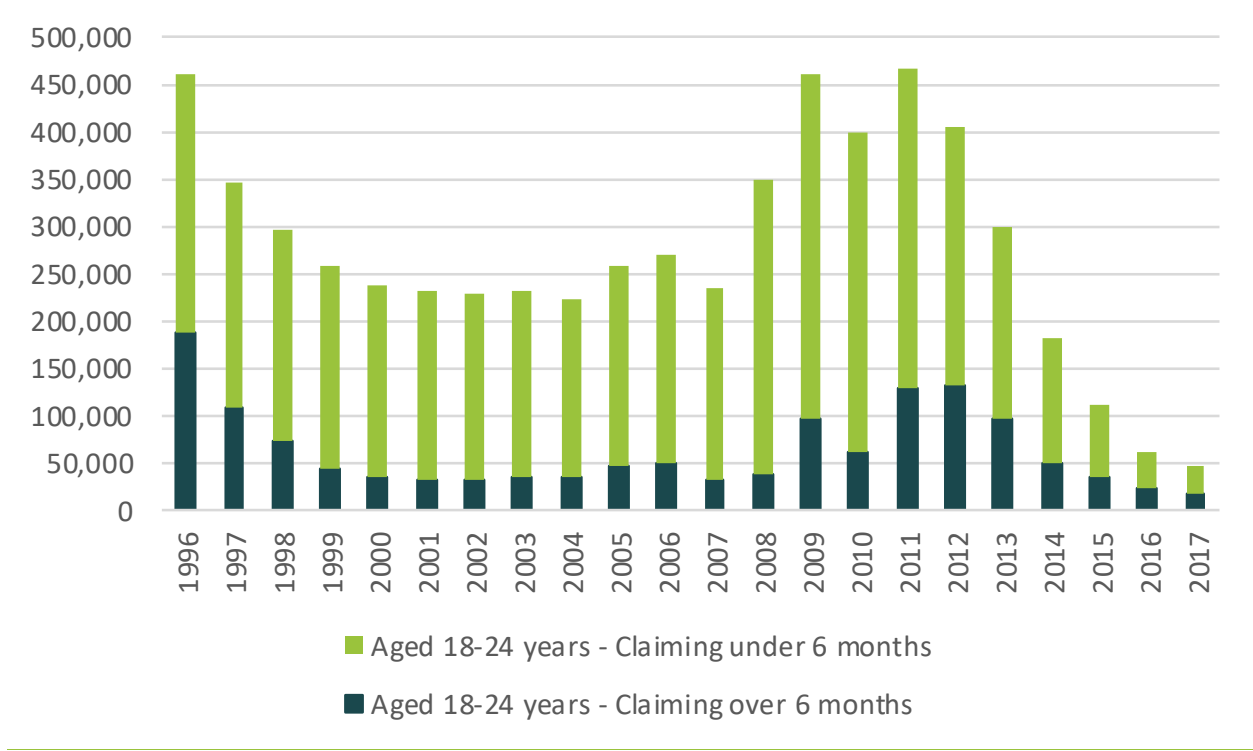

Source: JSA claims (via Nomis)

\section{Who is counted?}

The statistics presented above show a significant fall in youth unemployment over the medium-term. Talent Match was implemented during a period of considerable welfare reform. Concerns have been expressed that changes in the benefits system, such as increasing use of mandatory requirements and conditionality, including the use of benefit sanctions, may have led young people who would otherwise claim benefits not to do so. In written evidence presented in September 2016 to the House of Commons Work and Pensions Committee's Enquiry on 'Employment Opportunities for Young People', ${ }^{1}$ the Learning and Work Institute estimated that data showed that: "the proportion of unemployed young people (not counting students) who are not claiming Jobseeker's Allowance and therefore are not receiving official help with job search is now 59.7 per cent and has risen by more than thirty percentage points since October 2012."

Overall, this suggests that there is a sizeable proportion of young people who are out of work and 'hidden' from the official gaze of the benefits, employment and skills system. According to the Impetus-PEF Youth Jobs Index (2017), one in four 16-24year olds spend some time Not in Education, Employment or Training (NEET), with over 800,000 spending a year or more in NEET. This suggests that despite what conventional statistics suggest, unemployment remains a deep-seated issue which will not simply go up and down in line with the national economy. For individuals who are outside the labour market for longer periods, there is well established evidence around the longer-term effects in terms of wage scarring, but also physical and mental health. ${ }^{2}$ ${ }^{3}$ So, for example, a period of unemployment of say 12 months may have a lifelong impact not just on someone's future career progression (affecting their lifetime earnings) but also on their physical and mental health.

\footnotetext{
${ }^{1}$ House of Commons Work and Pensions Committee (2017) Employment opportunities for young people: Ninth Report of Session 2016-17. House of Commons, HC 586.

${ }^{2}$ ACEVO (2015) Coming in from the cold; why we need to talk about loneliness among our young people.

${ }^{3}$ McQuaid, R. (2015) Multiple scarring effects of youth unemployment. 10.13140/RG.2.1.1300.4964.
} 
Research using the Longitudinal Education Outcomes (LEO) dataset, ${ }^{4}$ shows that disadvantaged young people are twice as likely to be NEET as their better-off peers and that this gap has remained consistent over the period from 2010 to 2017 . The gap is even larger in the North East and in Yorkshire \& the Humber and smaller in London - suggesting that local labour demand may play an important role in regional variations in young people's experience. At a national level, half of the gap between disadvantaged young people and their better off peers can be explained by differences in qualification levels, suggesting that additional support needs - such as mental health support and housing advice - need to be addressed too, as education and training alone cannot bridge the gap.

\subsection{About the partnerships}

There were 21 Talent Match partnerships across England, each covering a separate Local Enterprise Partnership (LEP) area, and each led by a voluntary organisation. They are listed in Table 1.1 below.

Table 1.1: LEP areas and lead partner organisation

\begin{tabular}{ll}
\hline LEP area & Lead partner \\
\hline Black Country & Wolverhampton Voluntary Sector Council \\
Cornwall \& Isles of Scilly & Real ldeas Organisation \\
Coventry \& Warwickshire & Coventry Solihull Warwickshire Partnership Ltd \\
Derbyshire \& Nottinghamshire & Groundwork Greater Nottingham \\
Greater Birmingham \& Solihull & Birmingham Voluntary Service Council \\
Greater Lincolnshire & The Prince's Trust \\
Greater Manchester & Greater Manchester Centre for Voluntary Organisation \\
Humber & Humber Learning Consortium \\
Leeds City Region & Your Consortium \\
Leicester \& Leicestershire & The Prince's Trust \\
Liverpool City Region & Merseyside Youth Association \\
London & London Youth \\
New Anglia & Prince's Trust \\
North East & The Wise Group \\
Northamptonshire & Enable \\
Sheffield City Region & Sheffield Futures \\
South East & Prince's Trust \\
Stoke on Trent \& Staffordshire & Lichfield \& District Community \& Voluntary Sector \\
Tees Valley & Prince's Trust \\
The Marches & Herefordshire Voluntary Organisations Support Service \\
Worcestershire & The Shaw Trust \\
\hline
\end{tabular}

Five of the 21 partnerships were led by either a Voluntary Sector Council or other local infrastructure organisation. A further five partnerships were led by the Prince's Trust. Two other national VCS organisations also lead partnerships: the Wise Group in the North East; and the Shaw Trust in Worcestershire. The remaining nine partnerships

${ }^{4}$ Gadsby, B. (2019) Research Briefing 6: The Long-term NEET population. Impetus. 
were led by local specialist VCS organisations operating over a smaller geographical scale, but often still sub-regional or regional in terms of coverage. Two of these, Humber and Leeds City Region, were consortia based organisations (see also section 4.2 below). This approach was taken for a number of reasons, in terms of the organisations who came forward to deliver the programme in local areas but also the desire by the Fund to develop a test and learn approach designed to meet the needs of each area. 


\section{About the evaluation}

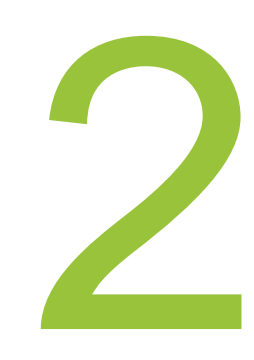

\subsection{Aims and objectives}

A key rationale for the evaluation was to support and help the Talent Match partnerships. This was through the sharing of good practice and evidence around what works. The evaluation also sought to inform future policy and practice to address youth unemployment, and assess the effectiveness of an approach which placed young people at the heart of the programme.

The overall requirements for the evaluation were as follows:

- To track the success of the programme and projects and interventions within it.

- To identify what works well, and what does not, for whom and in what circumstances.

- To share learning and improve practice (including amongst grant holders).

Key aspects of the evaluation for the Fund included:

- Estimates of the costs and benefits to society and the state of intervening with young people aged 18-24 who have been out of education, employment or training for 12 months or more.

- An evaluation of whether the principles in the programme (the partnership approach, the involvement of young people etc) have made a difference.

- A better understanding of the kinds of approach to intervention that work well, with whom and why, at different stages of the young person's journey toward and into sustained employment.

- A better understanding of how those approaches can be implemented.

\subsection{An overarching framework}

The over-riding aim of the evaluation was to provide a robust assessment of what works in assisting unemployed young people into sustainable employment and to disseminate this knowledge and evidence more widely.

There were five guiding principles of the Talent Match programme:

- engaging young people in all aspects of delivery and evaluation;

- providing structured opportunities for young people;

- a person-centred approach; 
- $\quad$ supporting local solutions;

- $\quad$ strong and positive communications.

These principles called for a responsive approach to capturing change. The 21 partnerships operated in widely differentiated local labour market contexts, focused on different issues and barriers, and varied in terms of their experience and delivery capacity.

The evaluation of Talent Match was thus multi-faceted and involved the following key components:

- Collection of information from each partnership in the form of a Common Data Framework (CDF). All participants joining the programme completed a CDF questionnaire and were followed up at $3,6,12,18$ and 24 month periods. This generated one of the most comprehensive datasets ever assembled on young people and their experience of finding fulfilling employment.

- Local labour market analysis. The evaluation profiled the local labour market conditions for each Talent Match partnership to help understand the labour market contexts in which each partnership was working and how these changed over time.

- Typology of interventions and partnerships. A key aspect of Talent Match was the 'Test and Learn' approach the Fund used across its strategic programmes. As part of this the evaluation developed a typology of interventions to understand what worked in terms of supporting young people.

- In the first three years of the evaluation thematic research was undertaken with reports published on involving young people; partnership working; mental health; key working; employer engagement; and in-work support. Each of these reports drew heavily on partnership case studies. ${ }^{5}$

- Involving young people was at the heart of the Talent Match programme and the evaluation. The evaluation team ran placements for young people fromacross five partnerships to support evaluation, learning and disse mination activities. All placements received a dedicated mentor and were given opportunities to support a range of activities in CRESR.

\subsection{Learning}

Learning activities were run alongside the evaluation and included the following:

- The delivery of three biennial conferences $(2014,16$ and 18) co-designed and delivered between the evaluation team, the Fund, partnerships and young people.

- The delivery of dissemination events around the thematic research.

- Contribution to a range of local, national and international events on youth unemployment, engaging young people, policy makers and practitioners. Over forty such events were supported.

- Bespoke support to each partnership was provided to roll out the Common Data Framework in 21 partnership areas with follow up advice on the local analysis of CDF data.

5 Details of all the Talent Match reports and access to summaries and full versions is form here: https://blogs.shu.ac.uk/talentmatch/ 
- Contribution to the Fund's events to share practice across evaluation teams, advise on design of future programmes and to report on progress to the Talent Match team and the Fund's England Committee (the two main governance groups for the programme.

The evaluation team also wrote briefings for a range of audiences including informing submissions to the All Party Parliamentary Group on Youth Unemployment and to the establishment by the UK government of its Dormant Accounts initiatives. 


\section{How was Talent Match delivered?}

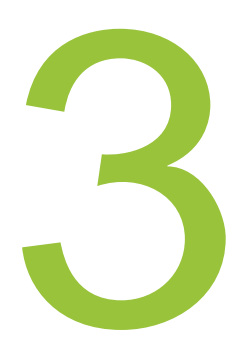

\subsection{Introduction}

Talent Match was designed to be an innovative youth employment programme. The Programme Guide for Talent Match set out the principles the programme was to follow which were designed to "enable thousands of young people to lead successful and fulfilling lives:

- Structured opportunities: Bringing together the public, private and voluntary and community sectors to create effective partnerships and coordination at the local level.

- Supporting local solutions: Matching the supply of talented young people to local demand for employment and enterprise.

- Asset based: A belief in people powered change and the ability of young people to improve their own circumstances and life chances with the right support. Young people should be engaged and involved in all aspects of the activities we fund.

- Strong and positive communications: Promoting positive images of young people and changing hearts and minds."

(Big Lottery Fund 2012, emphasis added)

Alongside the programme guidance the Fund also provided guidance to local partnerships on how they should form and be governed, clarified with other organisations (notably the Department for Work and Pensions) as to which young people were eligible for support, and during the life of the programme supported partnerships to engage in other opportunities (for instance from new funding programmes). The explicit assumptions in the original design document were also shaped and reframed by practice on the ground as individual partnerships had to engage with the practicalities faced in delivering Talent Match.

\subsection{Programme Costs}

This section provides an assessment of expenditure to 31 December 2018 - the main date for the end of the programme. ${ }^{6}$ Expenditure by the 21 partnerships up to 31 December 2018 was $£ \mathbf{9 6 . 1 4 4}$ million. However, there were differences in expenditure between partnerships:

\footnotetext{
${ }^{6}$ A small number of partnerships continued Talent Match funded activity into 2019 using underspends in the Programme.
} 
- $\quad$ London (£10.5 million), Black Country (£9.8 million), Greater Manchester (£9.0 million) and Sheffield City Region (£8.9 million) had been awarded and spent the largest amounts.

- Five partnerships spent less than $£ 1.5$ million: Greater Lincolnshire ( $£ 1.1$ million), Worcestershire (£1.2 million), Tees Valley (£1.4 million), The Marches (£1.4 million) and Stoke on Trent and Staffordshire ( $£ 1.5$ million).

The percentage of Lottery funding that has been spent by partnerships ranged from 77 per cent in The Marches to 95 per cent in London and the Black Country.

\subsection{How support was targeted}

As well as geographical targeting, partnerships also targeted specific sub-groups of unemployed people aged 18-24 years. This varied vary by area. Alongside the overall aim to target young people who were not in education, employment or training, partnerships also sought to support

- long-term unemployed;

- offenders;

- care leavers;

- lone parents;

- young parents;

- people with physical disabilities;

- people with learning disabilities;

- people suffering from mental ill health;

- carers;

- homeless people;

- BME groups;

- refugees / asylum-seekers;

- Gypsies and Travellers;

- people engaged in alcohol and/or substance misuse;

- those in isolated, rural areas;

- people with low levels of literacy and numeracy problems;

- people with low confidence levels.

Given this targeting approach and the fact that many of these sub-groups can be "hidden" from mainstream services and support, all partnerships were engaged in some form of outreach activity in trying to recruit individuals to the programme. A key aspect of finding "hidden" NEETS was the role played by VCS organisations, often working at very local levels, and of sustained outreach. In addition, most partnerships also had many referral routes on to the Talent Match programme with the most common being the Work Programme (typically Work Programme leavers still unemployed), local Jobcentre Plus offices and local authorities. 


\subsection{What support was provided?}

There was a relative degree of consistency in terms of partnership approaches to preemployment support. All partnerships engaged participants in some form of preemployment support, from an initial assessment on first engagement through to more specialised services and job search. The following were typical activities prominent in many partnerships. Apart from therapeutic support and peer mentoring - some of the more innovative approaches - all 21 partnerships provide these services or offered referral routes to them:

- initial assessment;

- development of an individualised plan;

- information, advice and guidance (IAG);

- basic skills (e.g. literacy and numeracy provision);

- soft skills (e.g. confidence building);

- employability skills;

- peer mentoring;

- therapeutic support;

- specialist support;

- job search.

Likewise, in terms of pre-employment training that takes place in the workplace, most partnerships offered:

- Pre-employment advice and support (often through a mentoring approach with an established entrepreneur or businessperson).

- Short term work experience and work placements to give an initial experience of employment.

- Structured volunteering with clear benefits for volunteers in terms of job skills.

- Internships, although these were less popular among partnerships reflecting to some extent, the bad press they have received in recent years as they were sometimes seen as an exploitative form of cheap labour.

Although the exact nature of pre-employment support inevitably varied by partnership and by individual, there was a degree of commonality in the kinds of support that Talent Match partnerships had in place. There was more divergence however about employer engagement and the inclusion of employer focused interventions.

Almost all partnerships performed some form of job brokerage - linking beneficiaries to labour market opportunities. A majority also engaged with employer mentors. That is, local employers who supported beneficiaries in various ways, such as through enterprise development and support. All partnerships also provide d opportunities for work experience or placements which provide beneficiaries with important experience in the work environment.

There was less consistency in terms of job creation activities and the development of demand-side interventions. Around half of partnerships provided employment opportunities directly through the Talent Match programme. Typically, this related to Talent Match apprentices employed through the projects but in some cases other job roles were filled by Talent Match beneficiaries. 
Direct employment at Talent Match partnerships aside, only eight partnerships engaged in employer focused activities involving the creation of jobs for Talent Match participants. These tended to be the larger urban partnerships and those which received the larger grant support: The Black Country, Birmingham and Solihull, Derbyshire and Nottinghamshire, Leeds, Liverpool, London and Manchester. New Anglia represented an outlier in this regard given its mixed urban-rural context and a relatively smaller grant award. However, it should be noted that a rationale of the Prince's Trust led partnerships, which include New Anglia, was to feed into other provision offered by the Prince's Trust.

Seven partnerships provided employersubsidies to those who employed Talent Match beneficiaries with a view to more sustainable employment further down the line. Again, these tended to be larger urban partnerships with sizeable grant awards.

\subsection{Key features of Talent Match}

\section{Geographical targeting}

An original aim of the programme was to target specific geographic localities containing concentrations of young unemployed people. In practice such targeting took place at two levels. Firstly, in identifying wards with high levels of claimant youth unemployment and secondly through targeting Talent Match at those Local Enterprise Partnership areas containing the highest concentrations of youth unemployment.

As the programme evolved partnerships tended to target wider areas. This was for two main reasons: youth unemployment fell nationally and in many of the target communities so a wider approach was needed to meet targets; and many partnerships developed expertise in working with particular groups of young people who were not necessarily concentrated in a few places.

Lesson: Future programmes need to give greater consideration in the design stage as to the targeting approach to be used and whether this meets the overall goals of the programme and is relevant to the needs of an area.

\section{Support to those furthest from the labour market}

A perennial issue in labour market programmes is how to target those furthest from the labour market - that is, those who may face the most significant barriers to entering work. The experience of many labour market programmes is that support ends up benefiting those closest to the labour market, many of whom may find work without support at all.

The Talent Match programme did not have a fixed approach to how those furthestfrom the labour market would be defined. By taking a voluntary and person-centred approach to supporting young people Talent Match attempted something quite different to these other approaches.

Lesson: The person-centred approach is a counter to a traditional 'top down' targeting approach. To some extent both are needed, and a real novelty of Talent Match was the understanding of needs as well as personal strengths or assets.

\section{Working at the Local Enterprise Partnership level}

Talent Match was the first Fund programme to be delivered at a Local Enterprise Partnership (LEP) level. A voluntary and community sector organisation was selected in each of the 21 LEP areas to act as a lead partner. A rationale of Talent Match was 
that by working at a LEP level Talent Match partnerships would be able to join-up their services for young people with the employer-side initiatives LEPs were pursuing.

The 'spatial scale' at which labour market programmes are implemented is an important consideration, especially for programmes working with young people defined as 'furthest from the labour market'. On the one hand it is commonly understood that geographic horizons expand as young people enter and then progress in the labour market. Therefore, approaches which can connect with young people at a very local level in the first instance are important. On the other hand, labour markets and the wider economy largely work at much larger scales, with economic development opportunities being developed in consideration of city-region and regional labour market opportunities. Marrying these supply (the young people entering the labour market) and demand (the requirements of employers) considerations is a key challenge for all those planning employment programmes.

Lesson: Targeting at a LEP level was an experiment and whilst some areas built good links with LEPs, this was not consistent and, in many areas, LEPs added little to the Talent Match programme. This variability in the capacity of LEPs has also been highlighted by the National Audit Office. ${ }^{7}$

\section{Youth Involvement}

Youth involvement was a key distinguishing feature of the Talent Match programme. Involvement in programme design and implementation was about empowerment, participation and in its broadest sense democracy. Involving young people was based on the following rationales:

- Representation: Young people involved in partnerships boards, groups and in delivery can help make programmes more legitimate to beneficiaries and effective in terms of the outcomes achieved. Representation does not mean that those young people actively involved in a programme either statistically represent all young unemployed people or that they are directly accountable to all young unemployed people. Nonetheless there needs to be a sense that they are representing wider concerns.

- Lived experience: Participatory programmes such as Talent Match help participants, young people, bring their lived experience of the realities of unemployment to bear in shaping programme design and implementation.

- Direct benefits: Those actively involved in partnership work often benefit enormously from this experience, with this being evident in terms of increasing confidence, understanding how partnerships work and in finding employment.

Youth involvement was a central component of the Talent Match programme. It should be stressed the involvement was not simply about representation (who was involved and to what extent in the oversight and delivery of the programme) but also about how the programme was delivered.

Lesson: The involvement of young people was found to be a crucial component to Talent Match and strengthened the design and delivery of the programme. It needs to be an integral part of programmes and not an add on element.

7 National Audit Office (2019) Local Enterprise Partnerships: an update on progress. London: NAO. www.nao.org.uk/wp-content/uploads/2019/05/Local-Enterprise-Partnerships-an-update-on-progress.pdf 


\section{Resourcing}

Talent Match was initially planned to be an $£ 108$ million programme with this funding allocated across 21 partnerships areas broadly in line with local levels of youth unemployment and the numbers of young people partnerships aimed to support. For instance, Talent Match Middlesbrough initially targeted two wards (and received around £1 million) whilst partnerships such as the Black Country covered a whole LEP area (and received £10 million).

Lesson: While partnership funding was significant it needs to be recognised that it is not a replacement to mainstream support or the need for Benefits which provide a decent social safety net. As the programme progressed greater links were forged between the partnerships and statutory bodies such as Jobcentre Plus.

\section{Progression to the labour market and holistic support}

A rationale of many youth employment programmes is that there is some form of progression towards and into work. This may go through steps including: engagement in a programme through community outreach; addressing major barriers (such as housing insecurity or physical or mental health issues); development of employment readiness and addressing practical and personal barriers; and then in work support. Each of these features was found in Talent Match. However, by taking a personcentred approach these steps did not necessarily proceed in a linear stepwise fashion - and holistic support was required.

Lesson: Talent Match demonstrated the benefits of taking a holistic and personcentred approach to supporting young people and this recognised that the model of progression, for those furthest from the labour market, varied in time, support and the nature of outcomes (both employment and wellbeing).

\section{Voluntary and community sector(VCS) led}

VCS organisations were the lead partners of the partnerships. The programme design assumed that the VCS had an advantage over other sectors in being user-focused and delivering programmes on a not-for-profit basis. In practice a range of types of VCS organisation came forward to lead partnerships, including local 'infrastructure' organisations, local youth work organisations, consortia of local organisations, and organisations with a nation-wide remit.

Lesson: VCS organisations brought a clear added benefit to the delivery of the programme, especially in terms of engagement and involvement of young people, being flexible in the support provided, and in outreach.

\section{Test and Learn}

A key assumption of the Talent Match was that it would take a 'test and learn' approach. This is in clear distinction to programmes which prescribe how they should be delivered at the outset or which involve some form of performance-based payment (such as payment by results). Talent Match had an explicit approach to embed innovation alongside a set of other design principles (youth involvement, local delivery etc).

Lesson: The Test and Learn approach provided the scope for partnerships to respond to local circumstances. A lesson was that many partnerships could have drawn more critically on labour market intelligence and evidence of prior interventions to support young people. 


\section{Fulfilling Lives outcomes}

The final rationale of Talent Match was that narrowly defined job outcomes are not all that matter. Each of the Fund's strategic programmes are about 'Fulfilling Lives'. In the case of Talent Match this assumes that the programme will have generated 'fulfilling' employment outcomes both in the short term (during the programme) and long term (over the working life of a beneficiary) including improvements in wellbeing (such as life satisfaction).

Lesson: The fulfilling lives rationale is an important one and has broadened the traditional scope of employment programmes. There is evidence that this holistic approach is essential for those furthest from the labour market.

\subsection{Who participated in Talent Match?}

By the end of December 2018, 25,885young peoplehad participated in Talent Match. ${ }^{8}$ This represented 93 per cent of the targeted number of participants that collectively Talent Match Partnerships set out to engage in their applications to the Fund.

Engagement in the programme varied. As might be expected with a voluntary programme some young people may have had minimal engagement. However, what became clear was that partnerships, overall, provided most support to those with greatest needs.

Figure 3.1 shows the number of partnerships targeting different sub-groups according to Partnership Survey data. ${ }^{9}$ All Talent Match partnerships responding targeted the long-term unemployed and the majority also placed a focus on people with mental health issues. A sizeable number of partnerships targeted young and/or lone parents.

\footnotetext{
${ }^{8}$ Based on baseline questionnaire responses to the Common Data Framework (CDF)

${ }^{9} \mathrm{~A}$ bi-annual survey of all Talent Match partnerships was conducted to gather data on a range of partnership variables including delivery models, targeting and youth involvement
} 
Figure 3.1: Sub-groups targeted

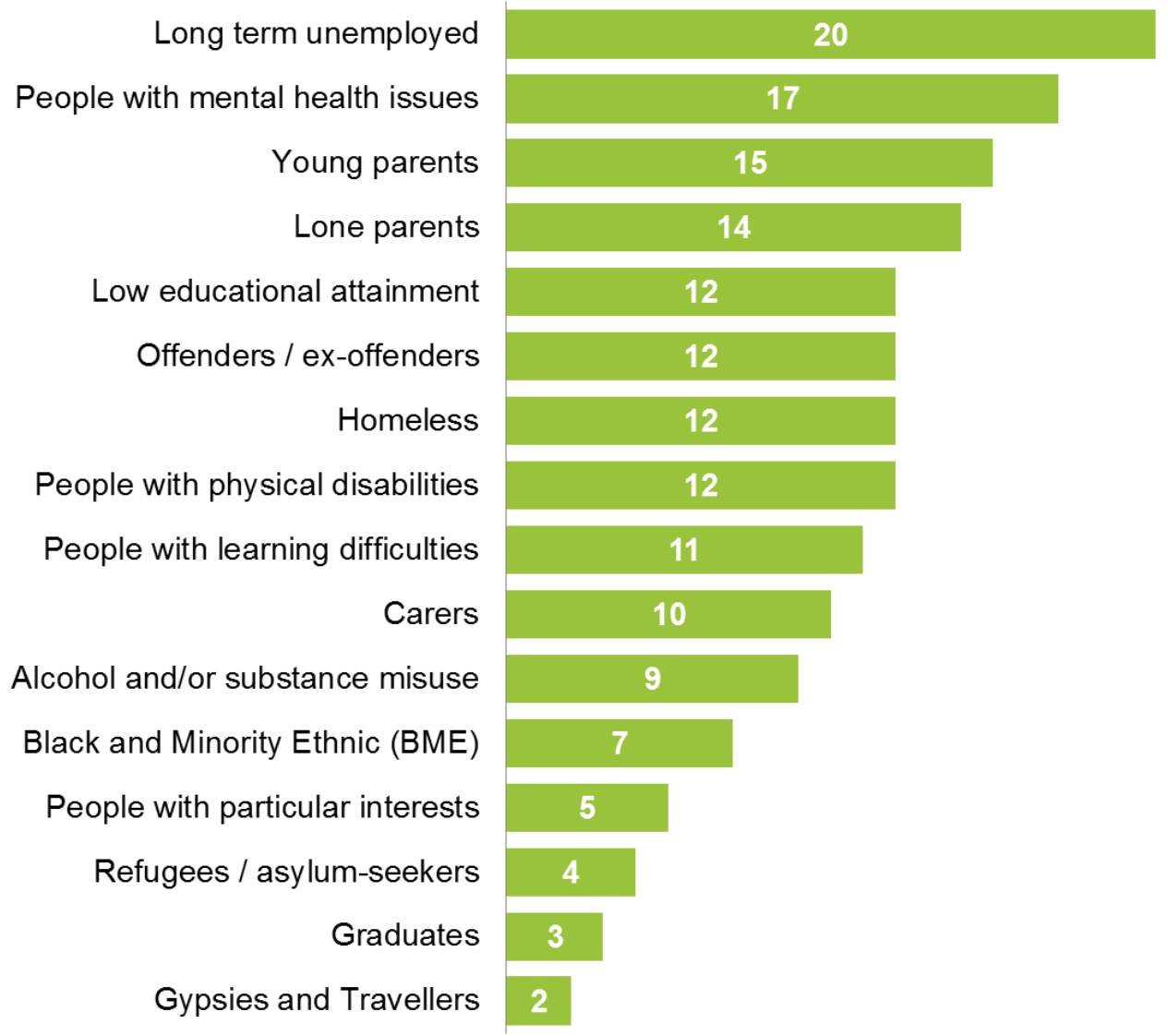

Base: 20

Source: Partnership Survey 2018

On some measures Talent Match participants were more disadvantaged than other NEETs in England (life satisfaction, qualifications and previous employment characteristics). On others they were less disadvantaged (parental status or disability).

Most Talent Match participants lived with their parents, and generally lived in more deprived neighbourhoods in urban areas.

Regardless of the nature of any place-based targeting approach adopted, Figure 3.2 shows that in practice most Talent Match participants lived in relatively deprived neighbourhoods. Neighbourhood deprivation in England is measured using the Index of Multiple Deprivation (acomposite measure of many variables including employment and housing). The CDF information shows that nearly two in five (38 per cent) participants are resident in the 10 per cent most disadvantaged areas in England and three in five (59 per cent) participants are resident in the 20 per cent most disadvantaged areas in England as measured by the Index of Multiple Deprivation. ${ }^{10}$ It indicates very strongly that Talent Match participants were more likely to live in deprived areas.

${ }^{10}$ This is a ranking of all neighbourhoods in England according to the 2015 Index of Multiple Deprivation published by the Department of Communities and Local Government. 
Figure 3.2: Percentage of Talent Match participants by level of deprivation in neighbourhood of residence

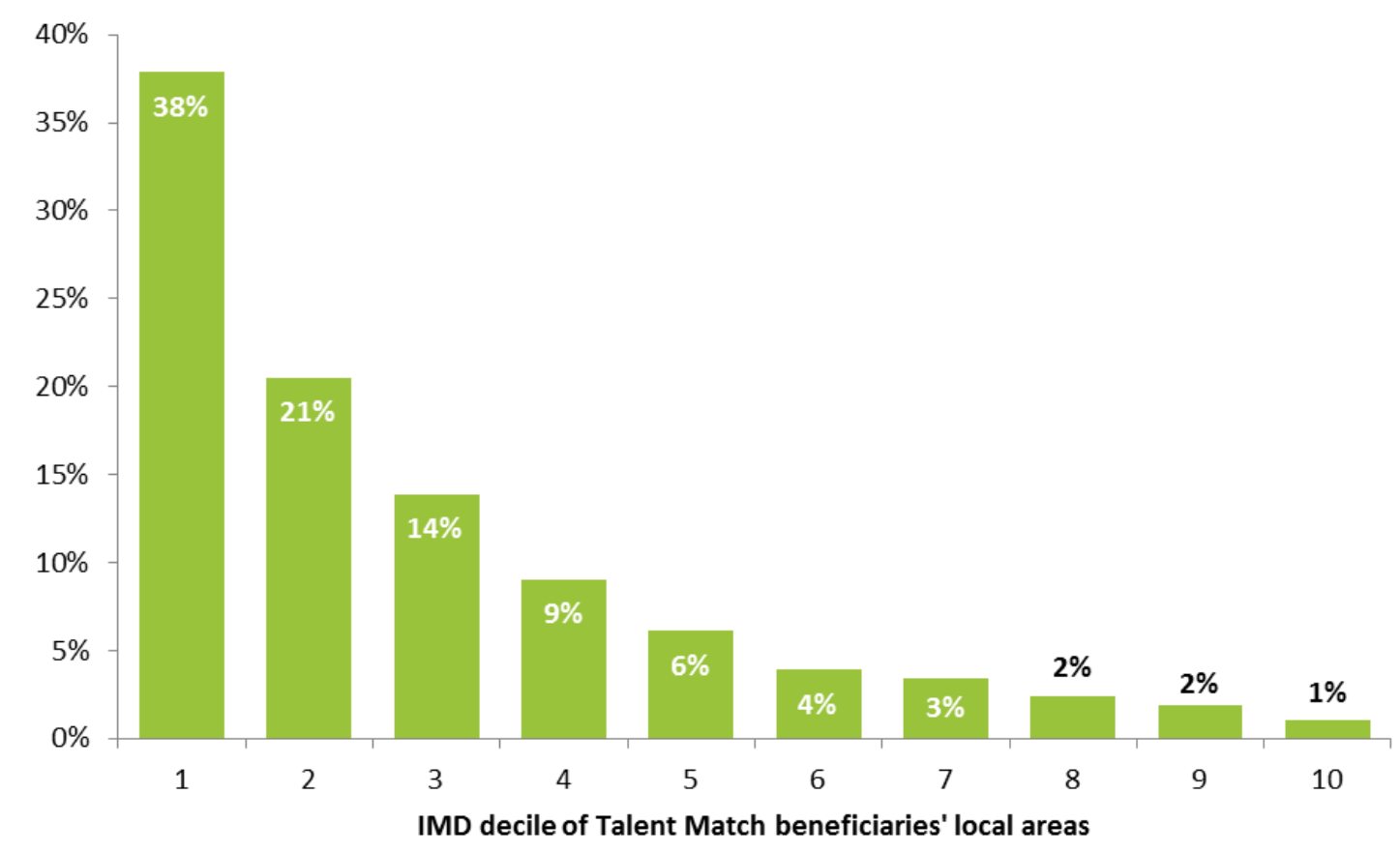

Source: Baseline survey (23,510), 2015 IMD data.

Note: IMD (Index of Multiple Deprivation) decile 1 denotes the 10 per cent most deprived neig hbourhoods in England and IMD decile 10 denotes the 10 per cent least deprived neighbourhoodsin England.

At the programme level Talent Match appeared to have generally provided services to a cohort of young people representative of NEETs nationally. The most notable difference relates to disability. Talent Match partnerships appear to have delivered services to fewer disabled NEETs than would be expected purely from their prevalence in the population. Many Talent Match participants however reported low levels of life satisfaction and a range of issues relating to poor mental health. A different measure of disability was used between the CDF and national statistics (which may account for a small amount of the difference), but perhaps more significantly Talent Match as a voluntary programme is likely to have engaged those young people who did not have disabilities which prevented them from entering employment.

\subsection{Conclusion}

Talent Match has broken new ground amongst youth employment programmes for its commitment both in design and delivery to actively involve young people. This was in part about involvement in decision making but it went much further in terms of adopting a person centred and asset-based approach to delivery. Many of the partnerships drew from prior experience in youth work to develop a distinctive approach to an employment programme.

At the same time Talent Match contained many similarities with previous youth employment programmes. It was largely focused on supporting young people rather than seeking to change the approach taken by employers and it was also voluntary, young people were not compelled through sanctions to engage with Talent Match. Local lead partner organisations through commissioning, partnership and contracting arrangements supported delivery partners to best meet the needs of young people. Talent Match focused less on, although there were exceptions, the active engagement and involvement of employers. 


\section{What has Talent Match achieved?}

\subsection{Individual outcomes}

The original aim of Talent Match was to support 40 per cent of participants into employment or self-employment. By the end of 2018:

\section{1,940 young people had secured employment / self-employment}

This represents 46 per cent of the 25,885 who had been engaged by the programme:

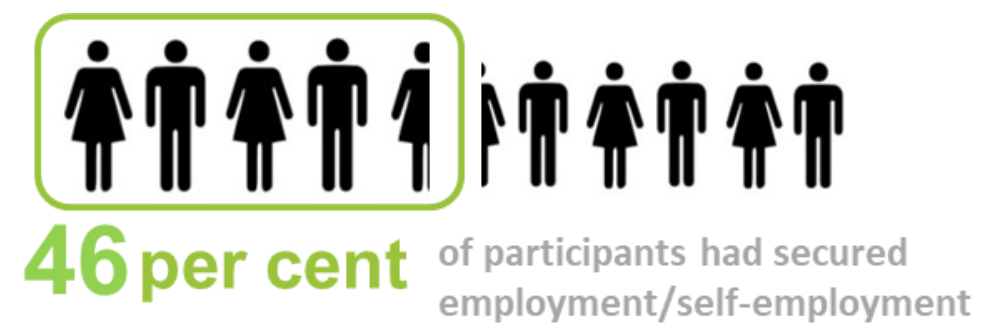

Nineteen of the 21 Talent Match partnerships had assisted two fifths (40 per cent) or more of their participants into employment/self-employment.

A second aim of the programme was that one fifth (20 per cent) of those supported would gain sustained employment or self-employment. Here sustained employment is defined as employment for at least six months or self-employment/enterprise for at least 12 months.

Our analysis suggests: ${ }^{11}$

\section{4,479 young people had secured sustained employment/self-employment}

\footnotetext{
11 The CDF has been used to estimate the impacts achieved from the programme. Responses received have been grossed up using weights to provide population estimates. More information about this procedure is provided in the Technical Report.
} 
When presented as a percentage of the 25,885 engaged overall:

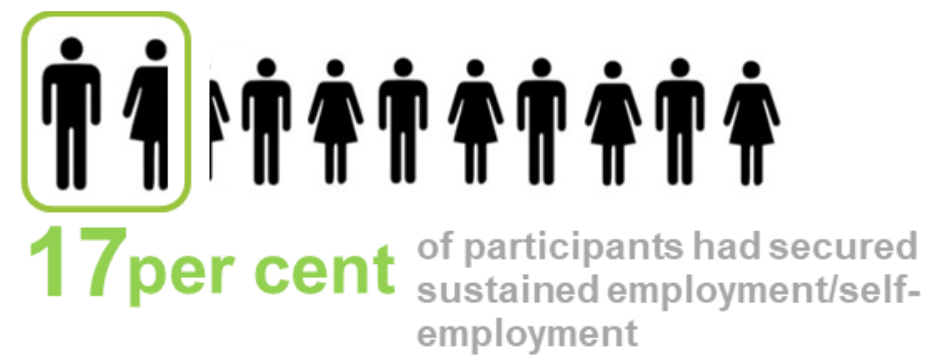

The young people securing employment tended to be satisfied with the employment they secured, and many reported that this was a stepping stone to future employment. Around 11 percent of those in employment were on zero-hours contracts however, with most of those wanting more guaranteed hours. Critically, and especially in those areas with weaker labour markets, nearly a half of young people felt they were underemployed.

On the whole young people saw employment as part of progression to better employment more aligned to their aspirations. To some extent Talent Match had helped clarify these aspirations and for many helped to build pathways to better employment. For those not securing employment, a significant group had felt they had moved closer to the labour market by the end of their involvement on Talent Match.

The evaluation explored subjective wellbeing. Wellbeing for Talent Match participants joining the programme was generally worse than that for the general population, but this gap, for most participants, closed during involvement on Talent Match. However, it was noticeable that Talent Match was not a guarantee of improved wellbeing and wellbeing worsened for significant numbers of participants (around athird). This should be a major concern for national and local policy makers. Talent Match approaches addressed some issues, but low or fluctuating levels of wellbeing have much deeper and longer-term causes.

\subsection{Partnership working}

Partnership structures have taken simple models. Common features include:

- A lead partner which in effect acted as an accountable body for the funding: overseeing grant management and performance, convening a wider strategic partnership and commissioning delivery partners.

- Delivery partner organisations which were contracted to deliver Talent Match activities. These were commissioned by the lead partner, developed in partnership between organisations, or proposed by delivery organisations.

- Wider partnership bodies. The lead partner formed a partnership group to oversee the programme and typically enlisted into these groups key local stakeholders. These members were typically at a senior level in their organisations and able to provide advisory support to the lead partner and delivery partners.

- Young people were involved in all partnerships, often both formally as members of partnerships groups but also in various delivery activities. 
Talent Match came at an important time with many mainstream employability programmes moving away from partnership approaches towards ones based more on contractual and payment by results procurement methods. Talent Match differed in its non-mandatory approach and in the leading role of VCS organisations.

Approaches to VCS leadership varied locally: in some cases, there was a more obvious lead organisation, whilst in others this was done through a process of deliberation and discussion. At the same time local areas were establishing 'shadow' partnership structures to develop proposals for funding.

The outcome of this phase was the emergence of four different types of lead organisation:

- National VCS organisations, in particular the lead role played by the Prince's Trust in five areas (New Anglia, South East, Tees Valley, Leicester and Leicestershire, and Lincolnshire), the Wise Group (North East) and Worcestershire (Shaw Trust).

- Local 'infrastructure' organisations (e.g. CVSs) in areas including Stoke and Staffordshire, Greater Manchester, Birmingham, Black Country, Coventry and Warwickshire, and The Marches.

- Local specialist VCS organisations including Cornwall, Northamptonshire, London, Sheffield City Region, Liverpool City Region, Nottinghamshire and Derbyshire.

- Consortia based organisations, including Humber and Leeds City Region.

At face value these organisations brought very different capacities and capabilities to bear on the programme. Their strengths were different, either in having specialist expertise in the involvement of young people, extensive experience the delivery of employment programmes, their connection with the local VCS or their national remit. The scale of the organisations also varied.

The main conclusions which can be drawn from the research into the models of partnership working in the Talent Match programme are as follows:

1. There is a distinct Talent Match partnership model which involves the following parties: The Fund; a lead VCS organisation; strategic 'stakeholder' organisations (such as LEPs and local authorities); and young people. However, the relationships between each varied from place to place depending on prior experience of co-working, capacity of different organisations and the overall focus for the Talent Match project. Local areas had considerable flexibility to shape their partnership within the framework of the programme.

2. The involvement of young people distinguishes Talent Match from most of other employment programmes. It was a key feature of all partnerships and 18 Talent Match areas saw it as critical to all areas of delivery. Only a co uple of partnerships felt it had constrained delivery in any way.

3. Lead partner organisations were vital to the oversight of Talent Match, for bringing Talent Match 'to life' in local areas, and where necessary for driving change. However, there was variation between areas as to the extent to which organisations felt able to lead the programme locally.

4. Delivery partners were engaged in different ways, but the majority felt they were able to help shape projects with the lead partner. This joint approach was vital but it also meant that lead partners had to work hard to secure and maintain the buyin of delivery organisations. 
5. Sustainability of partnership will only become clear after the closure of the programme. Whilst nearly all partnerships (whether the lead partner, wider partnership or the local area) saw Talent Match leaving a legacy, the end of the programme will leave a gap in support. Less than a fifth of delivery organisations said that they would continue to deliver the same level of service.

\subsection{Involvement of young people}

The involvement of young people in Talent Match has been one its most innovative features. Partnerships may have come with a commitment to an approach but in nearly all cases this evolved during programme delivery. Several themes have emerged from the evaluation:

- Partnership commitment and resources: Talent Match partnerships have devoted considerable time, resources and energy to the involvement of young people and have seen it, in line with the overall ethos of the programme, as a central aspect of Talent Match provision. There has been a wide variety of processes, structures and funding streams to support involvement across the Talent Match partnerships. What has emerged is a set of principles, or ways of working for young people's involvement which have shaped the overall Talent Match approach. Flexibility to respond to the changing needs and priorities has been paramount, as has ensuring that young people are not discouraged from involvement by limited opportunities forengagement and overly formal processes.

- Forms of participation: There have perhaps inevitably been relatively small numbers (compared to the total Talent Match beneficiary population) involved in structures and processes designed to influence the governance and delivery of the programme. This is in line with evidence from other initiatives which confirm that despite the existence of widespread opportunities for engagement only small numbers of programme participants will participate in formal involvement opportunities. Nevertheless, in each Talent Match partnership over 70 young people have shaped local provision, and this is an important difference to mainstream employment support programmes. Involvement also changed over time from supporting the design of the programme to more focused involvement in delivery.

- Characteristics of those involved: There is evidence that in Talent Match, involvement is associated with some personal characteristics and employment experiences. Notably, those young people who were involved were more likely to be those with disabilities and who had not experienced prior employment, when compared to their peers who were not been involved. This suggests that involvement in Talent Match acted as an important mechanism for supporting young people who were facing some of the most challenging barriers to labour market participation.

- Benefits from involvement: We found no significant link between involvement and employment, and those who have been involved in Talent Match were not more likely to gain employment outcomes. Nonetheless there were substantial individual benefits associated with young people's involvement: those who were involved moved closer to the labour market and reported greater gains particularly in confidence, communication skills and goal setting; this was often secured through work placements and volunteering. There was also no link overall with improved wellbeing, perhaps again reflecting the fact that many of the young people were experiencing challenges which included ill-health and disability which were beyond the scope of an employability programme.

- A model of co-production? Perhaps the key impacts of young people's involvement were, however, in influencing the work of Talent Match partnerships 
and other stakeholders. All partnerships benefited greatly from the involvement of young people. There was ample evidence from the programme that co-production with young people improved their engagement and participation in the programme (through young people's involvement in outreach and peer support); developed services that were responsive to young people's needs (and improved the quality of services); and influenced the policies and practices of organisations, including employers. These are important outcomes in themselves, and ones which are likely to enhance the experience and impact of employment support for all young people.

\subsection{Progression to employment and other outcomes}

This section of the report looks at those groups who have benefited most from Talent Match - in terms of how individual participants have progressed towards employment and other outcomes. The analysis draws on the CDF. Some of the key findings are outlined below with tables showing progression against different sets of characteristics.

Figure 4.1 shows that young people without a disability (limiting or non-limiting) were more likely to secure employment, compared to those with a disability. Heterosexual young people were more likely to secure employment compared to those not in this group. White young people were less likely to secure employment than those in other ethnic groups. Young women were more likely to receive seven or more forms of support but less likely to secure employment, compared to their male counterparts.

Figure 4.1: Securing employment by protected characteristics/equalities

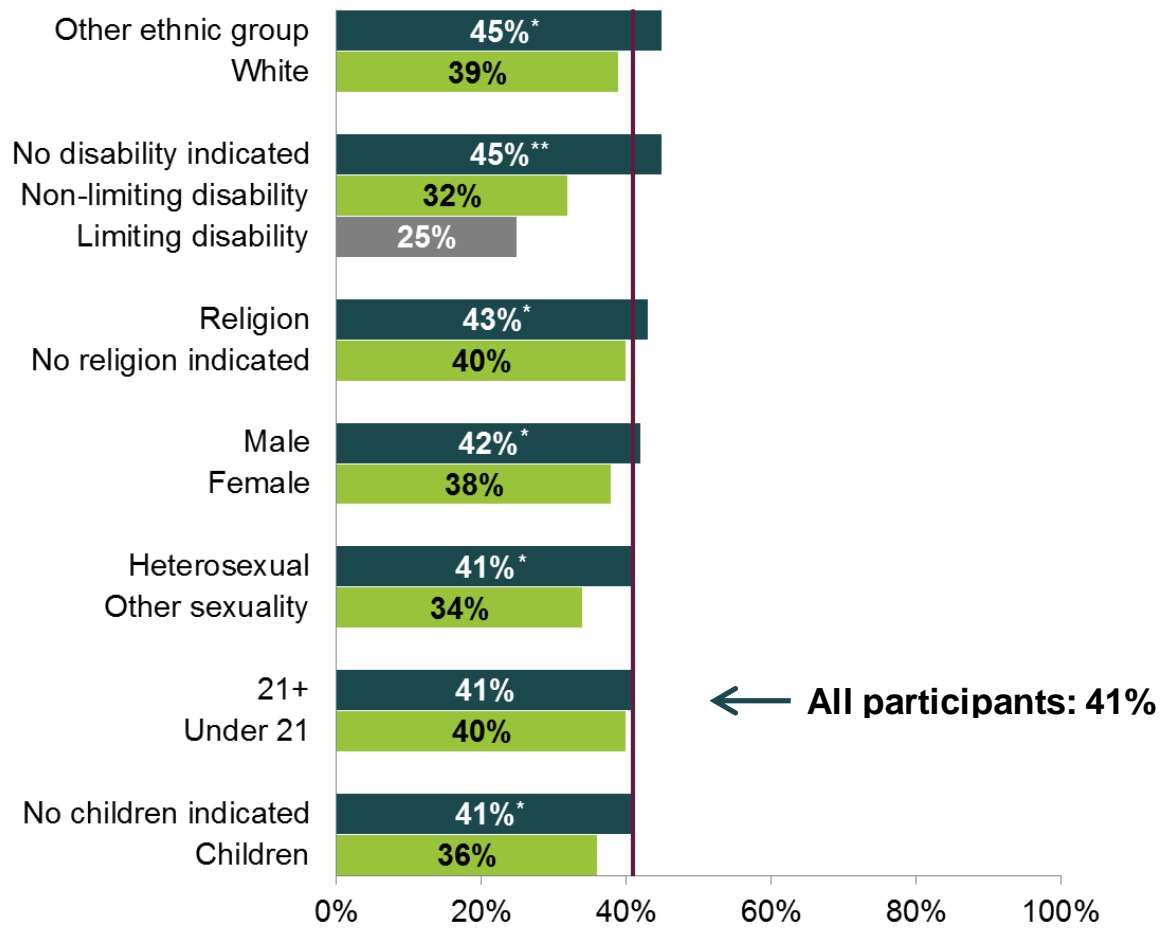

Min base: 11,346

Note: Results are based on two-sided tests with significance level 0.05 level. For each significant pair, a star appears on the bar indicating the larger proportion.

**indicates a significant difference between; no disability indicated and non -limiting disability; no disability indicated and limiting disability; and non-limiting disability and limiting disability 
Figure 4.2 shows that young people with five or more GCSEs at $A^{*}-C$ were also more likely to secure employment. Young people in receipt of benefits, and those who had adverse life experiences (one or more of being in the care of the local authority, a criminal conviction, alcohol or drug misuse, mental ill-health or homelessness) were less likely than those without these characteristics to secure work.

Figure 4.2: Securing employment by other baseline characteristics

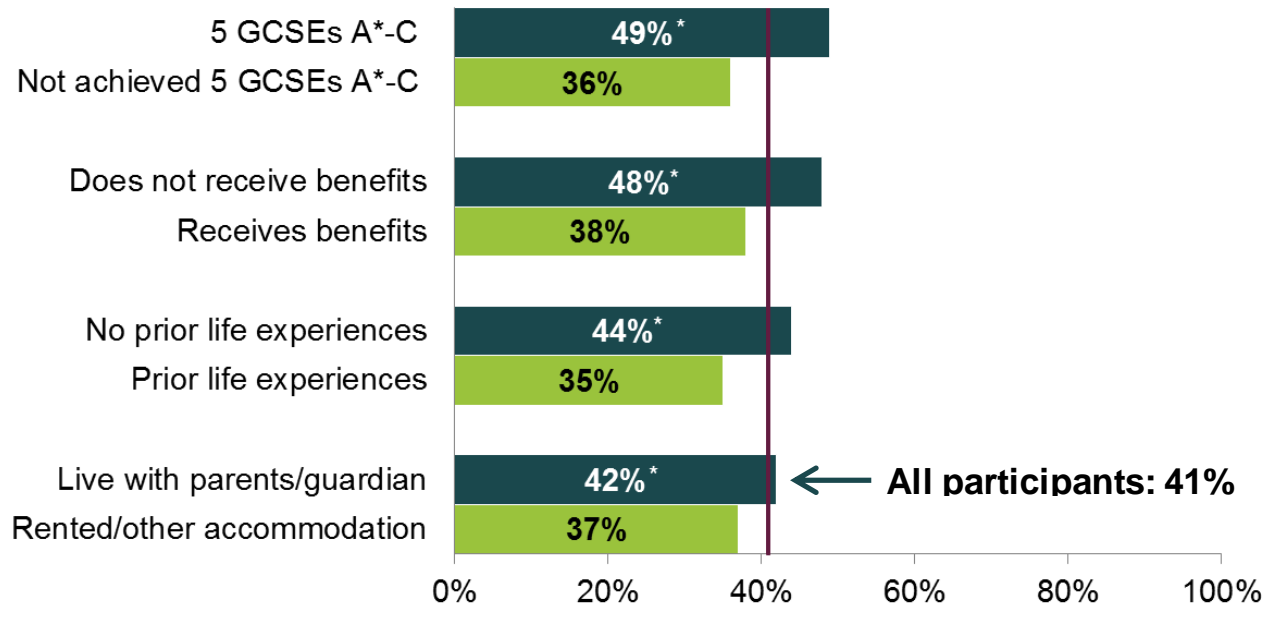

Min base: 11,329

Note: Results are based on two-sided tests with significance level 0.05 level. For each significant pair, a star appears on the bar indicating the larger proportion.

We were also able to explore which types of support were associated with greater levels of progression. Talent Match participants who had received larger packages of support ${ }^{12}$ were more likely to secure employment than those who had received less support. Types of support positively associated with securing employment were financial support, peer mentoring, support with travel, support addressing practical barriers, advice on personal development and information, and advice and guidance.

Overall, nearly one-fifth of Talent Match participants sustained employment. Findings are like those relating to securing employment, in that some characteristics are associated with an increased likelihood of securing sustained employment. The analyses of securing and sustaining employment highlight the positive role of in-work support (which is confirmed by evidence from the thematic study on in-work progression). ${ }^{13}$

In terms of well-being, over three-quarters of Talent Match participants (78 per cent) who initially recorded a low well-being score went on to record a higher score at a later stage. ${ }^{14}$

Characteristics associated with significant improvements in well-being scores include:

- Having a non-limiting disability (87 per cent, compared with 80 per cent of those reporting no disability and 72 per cent of those with a limiting disability).

\footnotetext{
12 Defined as seven or more interventions.

${ }^{13}$ Green, A., Barnes, S-A., Gore, T. and Damm, C. (2017) In-work support: What Is the role of in-work support in a successful transition to employment?, Talent Match Case Study Theme Report. Sheffield Hallam University, University of Warwick, Big Lottery Fund. https://www4.shu.ac.uk/research/cresr/sites/shu.ac.uk/files/tm-in-worksupport-report.pdf

${ }_{14}$ This analysis focuses only on those reporting a 'low' sco re at baseline. Those reporting a higher score at baseline have been excluded. At the time of analysis, this included 2,776 Talent Match participants.
} 
- Having no adverse prior life experiences (83 per cent, compared with 74 per cent with adverse prior life experiences).

- Having children (81 per cent, compared with 77 per cent for those with no children).

The first two characteristics are significant in terms of scale, and highlight the additional levels of support that some groups of young people may need to achieve well-being improvements.

\subsection{Talent Match legacy - the future of employment support for young people}

We looked at the future of the Talent Match partnerships at three levels: through the lens of the lead partner; the delivery partnership; and the local area.

\section{Lead partner}

Eleven out of the 21 partnerships stated that they have funding to continue some aspects of the Talent Match programme. When asked to provide details on this funding the majority indicated this resourcing was via the Fund either in the form of continuation funding or approvals to use underspends.

Partnerships have been able to access EU funding, typically for activities which are additional to Talent Match, such as in working with different age groups. For example, in Liverpool this has contributed to the development of an integrated service offer for young people aged from 14-29 years.

However, it was striking that most of the lead partners had not secured funding from other sources, whether through national or local programmes. Those that had were the exception.

\section{Delivery partners}

Only 18 per cent of delivery partner organisations indicated they had funding to continue any aspect of the Talent Match programme. This represents 18 organisations. When asked who this funding was from, 12 indicated this was via the Fund and five pointed to trusts or charitable foundations. For two organisations this funding was via the local police/crime commissioner, and six stated it was from an 'other' source with three of these mentioning European Union funding, such as the European Social Fund.

\section{Local areas}

Surveys of lead partners suggested that in about half of the areas Talent Match provision would continue to exist, in some form, beyond the programme funding period. It is also important to consider how the considerable emphasis on partnership working developed through Talent Match will continue to influence employment support for young people in Talent Match areas. Sustaining the collaborative models developed for Talent Match was a priority in most Talent Match areas. Eight partnerships indicated they intended to remain in place to deliver, while nine said their partnerships would no longer be in place but they would continue to work together. In most Talent Match areas, aspects of the Talent Match programme will also continue to influence local employability provision. This includes the ongoing involvement of young people in the design of services. Only two partnerships said there were no mechanisms locally to continue Talent Match provision.

This finding, despite the lack of new funding, is encouraging and demonstrates an important legacy of Talent Match beyond the employment outcomes it has supported. 


\subsection{Value for money}

This section assesses the additionality and value for money of the Talent Match programme. An assessment of additionality illustrates the extent to which benefits would not have been achieved without the programme. It is typically measured in a quantitative way and expressed as a percentage of the jobs achieved which would not have occurred anyway. As discussed above, a programme such as Talent Match will also achieve a range of non-employment outcomes such as improved well-being.

The evaluation adopted an approach which involved comparing the number of participants gaining a job against a matched group of similar young people from the Labour Force Survey (LFS); an employment survey run by the Office of National Statistics.

Upper and lower estimates of additionality were made. The upper estimate for employment additionality suggested 28 per cent of participants who gained a job would not have done so without participation on the programme; equivalent to 13 per cent $(3,298)$ of all Talent Match participants. This includes 1,237 young people obtaining a secure job (five per cent of all participants). Based on the lower estimate of additionality (nine per cent) 1,035 participants (four per cent of all participants) are thought to have gained a job that would not have done so without participation on the programme. This includes 388 young people obtaining a secure job (one per cent of participants).

This level of additionality is high compared to other initiatives such as the Future Jobs Fund ${ }^{15}$ or New Deal for Young People ${ }^{16}$ and in relation to wider evidence. ${ }^{17}$ The level of additionality reflects the scale of influence that Talent Match has on the factors affecting the likelihood of a young person finding a job, over and above other factors. This includes changes in personal circumstances, involvement in mandatory labour market interventions and job search as well as the growth in the supply of jobs in wider labour market that occurred over the five years that Talent Match ran. This realistic understanding of the additionality achieved by a well-funded youth employment initiative is an important marker to inform expectations for other initiatives and the financial returns that they may achieve.

The benefits of Talent Match should not simply be seen in terms of the employment and self-employment jobs gained. This is best highlighted through the improvements in job readiness and well-being, particularly for those young people who had low levels of job readiness and well-being when they first engaged with the programme. Individuals participating in Talent Match were overwhelmingly positive about their experience on the programme.

All employment programmes will bring benefit to society/public (mainly for the individuals directly benefiting from a programme) and for government in terms of reductions in spending and greater receipts from taxation. These are two different things and so are considered separately: one is the valuation of wider public benefits whilst the other is the narrower direct monetary (fiscal) effects on the public purse. It is important to consider both when developing a comprehensive assessment of the costs and benefits of an intervention.

\footnotetext{
${ }^{15}$ Department for Work and Pensions (2012) Impact and Costs and Benefits of the Future Jobs Fund. Department for Work and Pensions

https://assets.publishing.service.gov.uk/government/uploads/system/uploads/attachment data/file/223120/impact s costs benefits fjf.pdf

${ }^{16}$ Wilkinson, D. (2003) New Deal for Young People: Evaluation of Unemployment Flows, Policy Studies Institute

Research Discussion Paper 15. http://www.psi.org.uk/docs/rdp/rdp15-new-deal-for-young-people.pdf

${ }_{17}$ Card, D., Kluve, J. and Weber, A. (2015) What Works? A Meta Analysis of Recent Active Labor Market

Program Evaluations, IZA Discussion Paper No. 9236 http://ftp.iza.org/dp9236.pdf
} 
A key finding is that the value of the additional public benefits from Talent Match exceeded the cost: Drawing on the additionality estimates discussed above we find that:

- $\quad £ 3.32$ of public benefit has been created from every $£ 1$ of cost, based on the upper estimate of additionality.

- $\quad £ 3.08$ of public benefit has been created from every $£ 1$ of cost, based on the lower estimate of additionality.

The findings also confirm that supporting those furthest from the labour market, particularly in weaker labour market contexts, is more expensive and the costs will exceed the financial returns. Improved life satisfaction generates the most notable gain but when only 'real' money benefits are considered the costs of Talent Match significantly outweigh the benefits - mainly because many young people will still be obtaining some form of welfare benefits or subject to low levels of taxation.

The evaluation has not considered the potential longer-term benefits of Talent Match for example in terms of the prevention of scaring effects (either to income or health). Although there is an established body of work that has considered the effects of unemployment on later employment outcomes it has not been possible to apply these estimates to the evidence generated from Talent Match, particularly given:

- The extended periods of unemployment that many Talent Match beneficiaries had experienced may already have had a scarring impact.

- The limited evidence on lasting employment outcomes for participants: only 17 per cent gained sustainable employment.

- Many Talent Match participants gained part time and low-income employment, which is less likely to counter previous scarring, at least to the extent estimat ed in the literature.

\subsection{Conclusion}

A concern with sustaining the legacy of Talent Match is of course the lack of clarity as to where future funding may come from, with considerable uncertainty following the UK leaving the European Union, and in relation to the future policy landscape for youth employment initiatives.

With the likelihood of a recession and an increase in youth unemployment in the next two years the needs of those young people furthest from the labour market will need to be addressed alongside those of other groups. 


\section{Lessons for future policy}

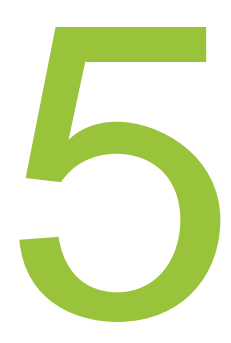

\subsection{Introduction}

A key lesson to emerge from Talent Match is that any full assessment of its impact on youth unemployment needs to be realistic. The total programme spend, whilst significant for the National Lottery Community Fund, was far less than the spending of mainstream government programmes and could only make a small effect at a local economy level.

It is also important to recognise a significant proportion of Talent Match resources were targeted at those young people furthest from the labour market, and for some, a job outcome may well not have been a realistic goal in the short term. It is therefore unrealistic to think that Talent Match alone could transform, at a local or national level, the employment outcomes for this group. Nonetheless, as Talent Match has demonstrated it has had significant impacts for individuals and contributed significantly to what we understand as the needs of many young people living and seeking employment in England between 2014-2018.

\subsection{Model of support}

Talent Match was a person-centred programme. It contained elements of 'work first' (getting young people into work quickly) and 'human capital' (developing skills, abilities and wellbeing) approaches. But what was striking was the relatively little attention given to the demand-side (i.e. working directly with employers).

A more holistic geographic approach would have balanced supply side features (developing young people through one-to-one support or assisting in overcoming practical barriers) with a closer and fuller engagement with local employers. Such attention may have opened opportunities to consider, such as:

- fuller engagement of employers on partnerships and in delivery;

- provision of in-work support, recognising the risks of participants not sustaining employment.

On the supply side (the young people themselves) a noticeable absence from Talent Match, and one which would be beyond the resourcing of the programme, was around skills development. Whilst education qualifications were not found to be a major gap faced by participants, work-related skills, whether in formal vocational qualifications or softer skills were missing.

Recommendation: A recommendation for future youth employment programmes is that greater emphasis is placed on combining work with young people, fuller engagement with employers, and supporting the progression of young people once in employment so that job and wider outcomes are sustained. 


\subsection{Labour market barriers and challenges faced by young people}

Talent Match worked with a diverse array of young people. Compared to the wider population of NEETs, Talent Match participants were more likely to have lower life satisfaction, less likely to have $5 A^{*}-C$ GCSEs and less likely to have previously held employment. However, they were more likely to have been in receipt of benefits and therefore less likely to be hidden NEETs.

One of the noticeable features of youth unemployment in the past decade has been the rise of young people who are NEET but also not claiming benefits. This group is beyond the statistical gaze of government (through the benefits system) but may also be out of sight of many local public and voluntary sector bodies. Individual partnerships attempted to understand and address this issue further but there remains a significant gap in our understanding of this groupand how to engage them at any significant scale in employment programmes.

The more evident barrier which was surfaced by Talent Match was around the low levels of reported wellbeing amongst participants. Most partnerships sought to address this need through a person-centred key worker model of support and there was individual evidence of how this contributed to the building of confidence. However, only one partnership (Liverpool City Region) put significant resources into working with the mental health needs of participants and made this a core feature of its programme.

Recommendations: Firstly in the context of an employment support system which uses strong forms of welfare conditionality (such as benefit sanctions and requirements to seek employment that may not be desired by the young person), resources will be required for engagement and outreach of those falling out of this system; and secondly, more needs to be done to address what were found to be low levels of wellbeing and more specifically poor mental health amongst participants.

\subsection{Understanding local labour markets and the needs of young people}

Talent Match operated at a range of geographic scales: from local authority wards up to initiatives covering whole Local Enterprise Partnership areas. The programme also operated in areas with varying levels of economic buoyancy. During the programme period the headline claimant rates of youth unemployment fell in all the Talent Match areas with some more significant falls in rural and south of England areas. Some of the changes could not necessarily have been predicted at the start of the programme and to some extent partnerships responded by either widening their geographic coverage or working more intensively with specific groups.

Two aspects supported the approach to targeting: firstly, labour market intelligence both nationally and locally helped partnerships understand what was occurring in their areas and how they could respond; and secondly the involvement of young people who could bring first-hand lived experience to inform the design of support.

Understanding local employment needs could have been better across all partnerships, however to some extent this was a core capability outside scope of most lead partners. Whilst some of the larger partnerships were able to draw on this knowledge, oftenfrom economic development partners, many areas were not. And finally lead partners often lacked effective knowledge of the needs of employers. Equally employers may show little interest in engaging in local employment support programmes.

Recommendation: The use of labour market data combined with local intelligence from young people and employers needs to be brought together more systematically to design and then refine labour market interventions. 


\subsection{Youth involvement}

Talent Match partnerships have devoted considerable time, resources and energy to the involvement of young people and have seen it as a central aspect of Talent Match provision. What has emerged is a set of principles, or ways of working for young people's involvement which have shaped the overall Talent Match approach. Flexibility to respond to changing needs and priorities has been paramount, as has ensuring that young people are not discouraged from involvement by limited opportunities for engagement and overly formal processes.

Lessons from the evidence on young people's involvement in Talent Match include:

- Young people's involvement has many forms and changes over time: The ambition to place young people at the centre of Talent Match was realised by providing a wide range of opportunities for involvement, building in opportunities for social activity and peer support, learning from experience and revising approaches over time. The ability of Talent Match partnerships to respond flexibly to the views and priorities of young people was important in encouraging, and sustaining, young people's involvement.

- Young people's involvement improves service quality: Some of the key impacts of young people's involvement were in influencing the work of Talent Match partnerships and other stakeholders, which included employers. This ensured that the voice of young people informed the development and delivery of provision across Talent Match areas. There would be clear benefits to embedding young people's involvement into future employment provision to ensure that it meets the needs of young people.

- Involvement is an important mechanism for supporting young people who are facing some of the most challenging barriers to labour market participation: The young people involved in Talent Match included those with disabilities and mental health issues. Opportunities for involvement enabled these young people to develop skills that they might not otherwise have obtained.

- Involvement helps young people to move closer to the labour market: Those young people who have been involved in Talent Match were more likely to enter formal education, secure an apprenticeship or work placement or take up volunteering than those who were not involved. These are important steps toward sustained employment, particularly for young people who don't have experience of paid work.

- Involvement supports young people to build skills and confidence: Young people who were involved in Talent Match reported greater gains particularly in confidence, communication skills, goal setting managing feelings, working with others and reliability. In future employability programmes there may be a rationale in seeking to support involvement of those groups for whom the se attributes and skills are particularly low.

- Involvement is only one part of a range of support that is needed to help young people to progress: Therewas no direct relationship between involvement and improved employment outcomes for young people involved in Talent Match. This reflects the challenges that this group were facing in finding work. Involvement should be a complement to, but not a replacement for, a range of other activities to support young people to overcome barriers to labour market participation.

Recommendation: Talent Match has proved the case for why young people should be actively engaged in the design and delivery of youth employment and support programmes. Although this brings higher up-front costs, the benefits come through as higher quality of service delivery, more rounded outcomes for young people (including 
work and wellbeing) and greater legitimacy of employment support amongst participants.

\subsection{Person-centred approaches and key working}

At first sight Talent Match brought together perspectives from youth work and from employment programmes. The evaluation found that to support those furthest from the labour market a holistic approach is needed in order to address the complex and multiple barriers some young people face. The holistic approach needs to consider the emotional and personal wellbeing, as well as the personal development of a young person. Key features of this approach include:

- Combining youth worker and careers guidance approaches. There is merit in a holistic approach that draws upon the tools of a youth worker and a careers guidance worker. The youth worker approach creates an open and safe environment for a young person to start their journey to employment. Then drawing upon the practices of a careers guidance worker approach, a young person can be supported in developing their knowledge and understanding of the labour market and the opportunities available to them.

- The importance of not neglecting careers guidance approaches in employability programmes. Careers guidance approaches are needed in order to help young people to start and progress with their journey into the labour market. Careers guidance workers have the expertise with which to help a young person receive and understand information about the labour market, as well as challenge assumptions and misunderstandings about the opportunities that may or may not be available to them in their local environment.

- The need for money to be allocated to key worker roles. Whilst it is recognised that key workers play an important role, this is not always reflected in the amount of funding allocated for key workers in business plans. As a result, this can preclude lead partners and delivery partners from specifying experience and qualifications in job adverts that they might otherwise have wished to include in person specifications. It is important that enough resources are earmarked for the key worker role at the planning stage of programmes.

Recommendation: The value of relational approaches between participant and employment support providers was found to be crucial to initial and ongoing engagement. This was especially the case for young people furthest from the labour market. Future programmes need to consider the appropriate balance across a range of support but also ensure that there are no significant gaps in this support.

\subsection{Partnerships and the local employment support ecosystem}

Local voluntary and community sector led partnerships were a key feature of Talent Match. The following were key drivers or enabling factors for partnership:

- Quality of partnership lead organisations and their capability to both lead and manage partnerships.

- Previous experience of partnership working which often meant partnerships did not need to be 'invested from scratch'.

- Involvement of young people in all aspects of partnership and which marked out Talent Match as offering something different.

- Test and learn approach adopted which meant partnerships could respond more effectively to internal and external change. 
These responses were common across the partnerships and indeed reflect the wider evidence on partnership working. The constraining factors were more context and programme specific:

- The long lead in period to Talent Match going 'live' meant that in some areas local labour market contexts and partners had changed by the time the programme was implemented.

- Other local initiatives to address youth unemployment risked creating confusion and added to the complexity of delivery.

- Difficulties in learning across delivery partners, as for some delivery partners Talent Match was a source of funding to deliver a specified service, rather than a wider endeavour to transform support for young people.

- The climate of austerity in the public sector and its effects on local VCS organisations may have curtailed opportunities for innovation and opportunities to find a local or mainstream funding source.

- Missing partners, or difficult relationships, hampered delivery in some areas with typical challenges being around engagement with Local Enterprise Partnerships, with Jobcentre Plus and with employer representative bodies.

Recommendation: The enabling and constraining factors have been common to grant based employment programmes in England for several decades. The time limited nature of grant funding means partnerships form and unform around the grant. This prevents the development of deeper and longer-term partnerships, of skills and capacity, and critically differing governance arrangements. At the heart of a response needs to be an effective programme of devolution, long term mainstream funding to support young people, and effective partnership working.

\subsection{Improving effectiveness and increasing outcomes}

Some of the ways effectiveness could have been improved have been outlined earlier in the section but key ones include:

- Improving progression. Talent Match made an important contribution to young people's progression into the labour market. Most Talent Match participants acknowledged that the support that they had received through Talent Match partnerships was helpful in supporting them to progress toward their employment goals. Furthermore, support for both work-related and non-work issues is needed to support young people to progress. A key part of the 'Talent Match journey' was found to be about improved wellbeing. Evidence points to the positive impacts of an integrated package of support (which includes key worker support) in helping individuals enter, sustain and progress in work. However, this support can be expensive, especially for individuals who are furthest from the labour market.

- Engaging employers. Employers have an important role in progression. Employability programmes are often criticised for their emphasis on individual participants rather than on employers. In any employment programme it is important to remember the role of the employer, since it is employers who are gatekeepers of jobs. For progression into employment to be achieved understanding employers' requirements and working with them, as appropriate, to support programme participants in work is beneficial. Talent Match thematic 
research on in-work support provided some good examples of working with employers to secure progression. ${ }^{18}$

- Understanding employment options. Progression is also influenced by the quality of jobs available and young people's understanding of employment options. The self-assessment of young people regarding the progress that they made highlighted how some felt thwarted by unfulfilling jobs. The Talent Match evidence suggests that the quality of jobs is important for well-being and in terms of opportunities for progression. This highlights the importance of attempting to match jobs with individuals' aspirations, while also using programme support to develop an understanding of alternative job opportunities. Thematic research on key workers and the role of high quality information, advice and guidance shows how this might be done. ${ }^{19}$

\subsection{Conclusion: sustaining support}

Finally, this report provides useful insights into sustaining the benefits of a youth employment initiative after funding ceases: it is never too early to address issues of sustainability; to give one example, the scale and nature of any longer-term support from mainstream agencies should be written into project appraisals. What Talent Match demonstrated is that the challenges faced by young people furthest from the labour market are deep seated and will not simply improve with an upturn in the national economy -these include barriers such as skills and employment experience, but also and perhaps more critically low levels of wellbeing and poor mental health.

Major changes have occurred in the policy landscape in England during the Talent Match programme. Foremost amongst these is the loss of the European Social Fund as a key long-term funding source for youth employment programmes. Whilst the ESF may be replaced as part of a 'Shared Prosperity Fund' commitments to do so are currently unclear, both in terms of the size of funding available and how this might be implemented.

The devolved arrangements in England remain incomplete with variable powers and funding existing across England. There is an opportunity for employment support and youth employment support to feature more strongly in any future devolved settlement and for long term funding to be made available to support young people furthest from the labour market.

\footnotetext{
${ }^{18}$ For further details of this research on in-work please see our thematic study. A blog is available here https://blogs.shu.ac.uk/talentmatch/blogs/?doing wp cron=1538665596.7831161022186279296875 and the longer report here: https://blogs.shu.ac.uk/talentmatch/files/2015/03/tm-in-work-support-report.pdf

${ }^{19}$ For further details of this research on the role of key workers please see our thematic study. A blog is available here https://blogs.shu.ac.uk/talentmatch/evaluation-blog-12-how-key-workers-can-help-young-people-progresstowards-work/ and the full report here https://blogs.shu.ac.uk/talentmatch/files/2015/03/tm-key-worker-report.pdf
} 


\section{Sheffield Hallam University}

\section{Talent Match Evaluation: A Final Assessment}

DAMM, Christopher <http://orcid.org/0000-0002-7355-3496>, GREEN, Anna, PEARSON, Sarah <http://orcid.org/0000-0001-5049-5396>, SANDERSON, Elizabeth <http://orcid.org/0000-0003-1423-1670>, WELLS, Peter <http://orcid.org/0000-0002-52004279> and WILSON, Ian <http://orcid.org/0000-0001-8813-3382>

Available from the Sheffield Hallam University Research Archive (SHURA) at:

http://shura.shu.ac.uk/26573/

\section{Copyright and re-use policy}

Please visit http://shura.shu.ac.uk/26573/ and http://shura.shu.ac.uk/information.html for further details about copyright and re-use permissions. 